\title{
Aluminum based Composites by Severe Plastic Deformation Process as New Methods of Manufacturing Technology
}

\author{
Agus Pramono ${ }^{1, \mathrm{a}}$, Alry Mochtar Jamil ${ }^{1}$ and Anistasia Milandia ${ }^{1}$ \\ 1, Department Metallurgy Engineering, University of Sultan Ageng Tirtayasa. Cilegon, \\ 42435 Banten, Indonesia
}

\begin{abstract}
Composites a material was developed to replace metal and alloys, because of the properties such as light weight and unique mechanical properties. Processing of aluminum-based composites has been developing by new manufacturing technology, namely severe plastic deformation (SPD), to produce unique of mechanical properties. Some of the methods used are; equal channel angular pressing (ECAP), accumulative roll bonding (ARB) and multi-axial forging (MAF). The results of some of these methods were compared with the latest method of new SPD, namely: repetitive press roll forming (RPRF). Based on grain morphology and mechanical properties, the result of RPRF has superior to another method. The properties produced by SPD technology was varies, the highest of hardness produced by RPRF process was 88 HV10, ECAP produced $65 \mathrm{HV} 10, \mathrm{MAF}$ was $46 \mathrm{HV} 10$ and ARB reached $50 \mathrm{HV} 10$. While the highest of tensile strength produced by MAF was $237 \mathrm{MPa}$ while the RPRF process just only around $147 \mathrm{MPa}$, but the ultrafine grains just only produced by RPRF method which is $0.9 \mu \mathrm{m}$, compared to other methods: MAF $1.2 \mu \mathrm{m}$, ECAP $5.7 \mu \mathrm{m}$ and ARB is not so far with MAF that is equal to $1.4 \mu \mathrm{m}$. The RPRF process can be recommended for the interest of the aluminum-based composite materials processing industry. Because currently some component product by industries have been substituted from metal alloy materials to metal-based composites.
\end{abstract}

\section{Introduction}

The new technology of manufacturing process by severe plastic deformation (SPD) has been developing rapidly as a processing of metals and alloys. By high pressure there will get ultrafine grained (UFG) in the material which will lead to the increase of mechanical properties. The main emerging technologies after forging and extrusion are equal channel angular pressing (ECAP), multi-axial forging (MAF) and accumulative roll bonding (ARB) [1]. Some of SPD technologies, such as ECAP, MAF and ARB, have been used for the development of composite materials. Therefore, grain miniaturization can be coupled by reinforcement from particulates for mechanical property enhancement [2-3]. To produce high mechanical properties on SPD required a long pressure cycles. Some of research on

\footnotetext{
${ }^{a}$ Corresponding author: agus.pramono@untirta.ac.id
} 
SPD works such as; ECAP performed by Langdon [4] to achieve $1.9 \mu \mathrm{m}$ grain size with tensile strength more than $100 \mathrm{MPa}$ required 11 cycles' as for the ARB process conducted by Argentero [5] in his research, requires 10 cycles of rolling compression to produce 113 $\mathrm{HV}$ with tensile strength $>100 \mathrm{MPa}$. Improved of mechanical properties on composites has been performed by Amirkhanlou [6] using new method accumulative press bonding (APB), to produce fine grains with a ultimate tensile strength of $180 \mathrm{MPa}$ from $88 \mathrm{MPa}$ base material, it takes 14 cycles. The APB process was developed based on the principle of accumulative roll bonding (ARB) process, but can be readily installed in both a laboratory and industrial environment. The APB process can be applied to sheet materials and thick billets of relatively large-scale dimensions, while the ARB process can only be applied to sheet materials [7-9]. This phenomenon does not change the long cycles to produce high strength by UFG. The development of the latest methods that refine the ARB and APB processes is repetitive press roll bonding (RPRB). RPRB is a process of SPD that combines repetitive pressing forces with the rolling forces, where the compression procedure is was done continuously to meet the cycles [10]. Compression on the RPRB process has two important roles in the processing of composite materials; First pressing force gives effect to the embedded of the reinforcement, either powder or fibres into the surface of the sample plate, so that there will be a face bond between the matrix and the coupled reinforcement, latter of the roll force providing contact on the surface which will result in the distribution of the reinforces dispersed into the composite contact plane [11]. This study aims to distinguish several of SPD methods that have been applied for composite materials, among the methods applied are ECAP, MAF, and ARB. In all, the SPD method is compared with the RPRB method, in application of application in the Industry, bonding on the material will change its name to forming because if it has been applied for certain component application then bonding phase will become repetitive press roll forming (RPRF).

\section{Materials and Experimental Methods}

The matrix material used for ECAP process were Aluminum series 1070 (AA1070) $/ \mathrm{Al}_{2} \mathrm{O}_{3}$ nano-fibers (ANF) as reinforced. For MAF and ARB used Aluminum series AA1100/Silicon Carbide ( $\mathrm{SiC}$ ) as reinforcement. As a comparison method the material matrix used on RPRF process is AA1070/ANF and in other hand AA1100 as matrix material with $\mathrm{SiC}$ as a reinforcement. The use of composite materials processed in SPD is presented in Table 1 to clarify the use of materials to the SPD process.

Table 1. Use of Materials for the SPD process.

\begin{tabular}{|c|c|c|c|}
\hline SPD Process & Matrix & Reinforcement & Form \\
\hline ECAP & $\mathrm{AA} 1070$ & $\mathrm{Al}_{2} \mathrm{O}_{3}$ & Powder/Fibers/Bars \\
\hline $\mathrm{MAF}$ & $\mathrm{AA} 1100$ & $\mathrm{SiC}$ & Plate/Powder \\
\hline $\mathrm{ARB}$ & $\mathrm{AA} 1100$ & $\mathrm{~B}_{4} \mathrm{C} / \mathrm{SiC}$ & Plate/Powder \\
\hline $\mathrm{RPRF}$ & $\mathrm{AA} 1070 / \mathrm{AA} 1100$ & $\mathrm{Al}_{2} \mathrm{O}_{3} / \mathrm{SiC}$ & Plate/Powder/Fibers \\
\hline
\end{tabular}

Characterization using Microscope Optical were used to determine the grain morphology and precipitate distribution, imaga-J software to know grain size, while the mechanical properties traced by hardness (HV10) testing to determine the ability of loading to plastic deformation and tensile strength to know the relationship of stress diagram to strain.

\subsection{Equal channel angular pressing (ECAP)}

Materials of composite by ECAP consist of AA1070 as matrix and ANF as reinforcement. AA1070 and ANF mixture by mechanically ball milling. The volume fractions used were 97:3\%. Milling process used $60 \mathrm{rpm}$ for 24 hours. After the process was complete the next 
stage preparation of compaction by wrapped on composite materials (AA1070/ANF) in copper tube and heated in a furnace with temperature $400^{\circ} \mathrm{C}$ during holding times one hour. Pressing process of ECAP in the single pass, shown in Fig. 1.a

\subsection{Multi-axial forging (MAF)}

MAF process stages were cutting AA1100 size $135 \mathrm{~mm}$ x $25 \mathrm{~mm}$ x $3 \mathrm{~mm}$ with thickness 3 $\mathrm{mm}$. The sample was brushed using a wire brush in the same direction. Before the grinding, process was done to smooth the surface; the material is first cleaned by acetone solution. Giving acetone is expected so that the material does not have dirt and no oxidation occurs. Then make a hole on each edge of the sample. The next step, done grinding and adding SiC powder, fraction of weight $0.2 \% \mathrm{wt}, 0.4 \% \mathrm{wt}, 0.6 \% \mathrm{wt} \mathrm{SiC}$. MAF principle that is after forging, material rotated $90^{\circ}$, the forging up to several times pass on each side. The process scheme is presented in the figure 1.b

\subsection{Accumulative roll bonding (ARB)}

The material used AA6061 as a matrix and SiC for reinforced. The sample was cutting by grinding to be: $2 \times 100 \times 10 \mathrm{~mm}$. Then the surface of the sticking sample is cleaned with a wire brush and acetone and marketed by grinding, both plates are neatly stacked and each surface is sprinkled with a powdered $\mathrm{SiC}$ and each edge of the plate is clamped with a rivet. The prepared sample was preheated using a muffle furnace with a temperature of $400^{\circ} \mathrm{C}$ and a holding time of 60 minutes. The heated sample is directly rolled using a rolling machine. A scheme of the ARB process of composites is presented in Fig. 1.c

\subsection{Repetitive press roll forming (RPRF)}

Type of materials used AA1100 and SiC, preparation begins by cutting a sample of AA100 sheets measuring $2 \times 1 \mathrm{~cm}^{2}$ into $2 \times 5 \mathrm{~cm}^{2}$. SiC as reinforce was used percent by weight $0.4 \%$. The next stage of surface preparation is done by cleaning the aluminum surface with a wire brush followed by surface grinding with a grinding machine. Then stacked with other samples that have been prepared with the prepared part of the surface, at the end of the sample in the friction weld, for the previous experiment used copper wire clamp, copper wire clamp still allows the plate to shift so that with a very strong clamping weld clamping and avoid shift plate. Heating sample $350^{\circ} \mathrm{C}$ for 1 hour of pressure begins with maximum load capacity of 10 tons, then rolling process with percent reduction of $50 \%$. Procedures of the RPRF Experiment shown in Fig. 1.d 


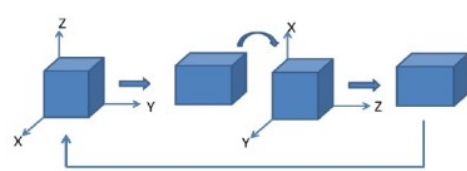

a)

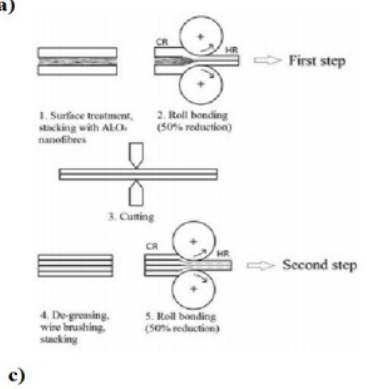

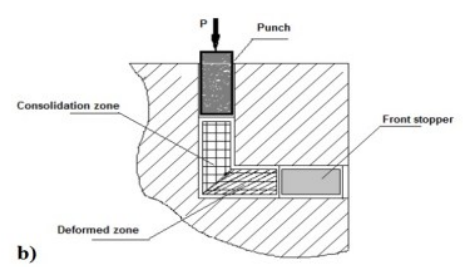

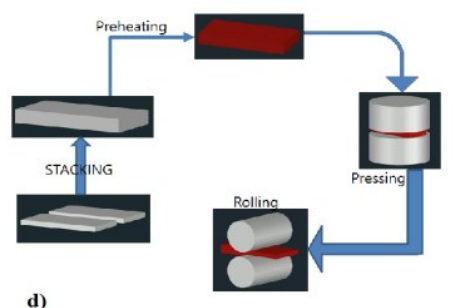

d)

Fig. 1. The technology process of SPD on Aluminum based composite: a) Multiaxial forging (MAF) [13]. b). Equal channel angular pressing (ECAP) [12]. c) Accumulative roll bonding (ARB) [14]. d). Repetitive press roll forming (RPRF) [10].

\section{Result and Discussion}

Investigation of composite by SPD was conducted to determine the characteristic of mechanical and physical. For microstructures behaviour used microscope optic, was traced to determine the grain morphology and deployment precipitates on grain. Image-J software was used for quantitative microstructure analysis calculation of the grain size. Each SPD method is traced to its mechanical properties, such as the mechanical properties of ECAP, MAF and ARB processes, compared to the new of RPRF method. Investigation of grain size on microstructure to know the relation of mechanical properties.

\subsection{Microstructural analysis}

The microstructure of grain morphology on ECAP process of composite was observed, seen of $\mathrm{Al}_{2} \mathrm{O}_{3}$ shaped fibres, white, spread evenly among the aluminum matrix shown in fig. 2 a. Aluminum as matrix and $\mathrm{Al}_{2} \mathrm{O}_{3}$ as a reinforcement is a suitable composite material because at the time of ECAP compression, tensile and compressive stresses gave an effect on the twinning movement of dislocation in the dies that makes the diffusion work effectively, so as to form strong grain bonds [15]. In The micro-structures of ECAP process using 50-100X magnification, it appears that the alumina flakes are spread evenly on each side of the aluminum matrix, proving that aluminum with alumina has good grain bonds due to the combination high pressing and tensile forces on ECAP processes. Figure $2 \mathrm{~b}$. shown the result microstructure of aluminum-based composite by MAF process, with $\mathrm{SiC}$ as an reinforcement. Visible grains of equaxed shape, the compressive stress will tend to cause the grain change to be equilateral [16], this essential grain change will improve mechanical properties such as strength and hardness. 


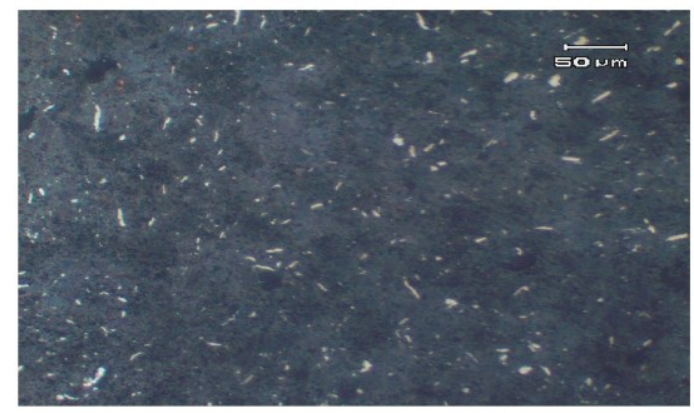

a

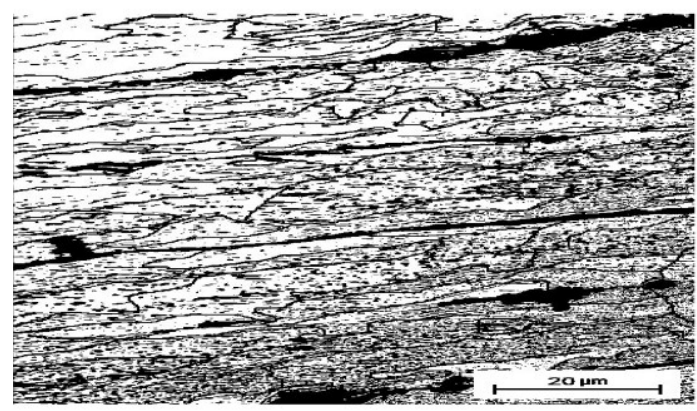

C

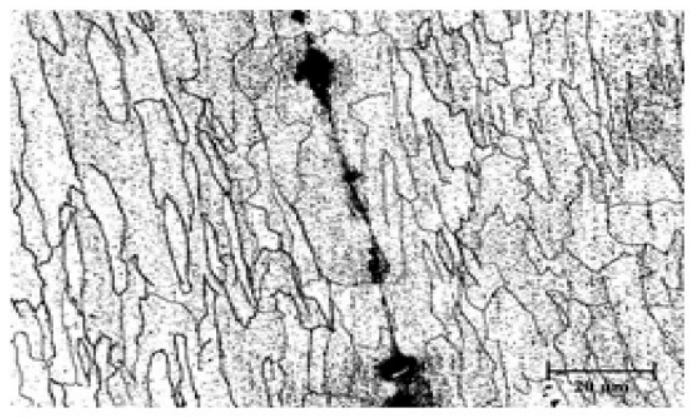

b

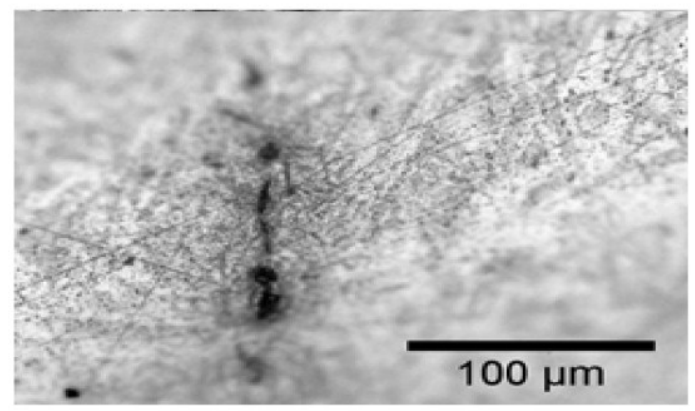

d

Fig. 2. Result of microstructural Optical a) Composite $\mathrm{Al} / \mathrm{Al}_{2} \mathrm{O}_{3}$ by ECAP b) Composite $\mathrm{Al} / \mathrm{SiC}$ by $\mathrm{MAF}$ c) Composite $\mathrm{Al} / \mathrm{SiC}$ by $\mathrm{ARB}$ d) Composite $\mathrm{Al} / \mathrm{SiC}$ by $\mathrm{RPRF}$

For $\mathrm{Al} / \mathrm{SiC}$ composite by $\mathrm{ARB}$ process it is seen that a lot of black porosity dominates the matrix area, fig $2 \mathrm{c}$. this is the result of poorly diffusion between the Aluminum as a matrix to $\mathrm{SiC}$ as reinforced, although at the farthest part of the grain morphology interface it turns to equaxial but the porosity dominance does not increase enough its mechanical properties. Figure $2 \mathrm{~d}$. shows the microstructure of $\mathrm{Al} / \mathrm{SiC}$ processed by RPRF. Seen the formation of a closed interface line across the boundary by the missing line between the interfaces, based on [14] the missing line is the result of a grain delamination process that results in a particle shift that covers the interface boundary line, it indicates the diffusion occurs perfectly.

\subsection{Mechanical Properties}

Hardness was compared between each method, the highest hardness was found in $\mathrm{Al} / \mathrm{SiC}$ composite by RPRF process that was $88 \mathrm{VH} 10$, when compared with Composite $\mathrm{Al} / \mathrm{Al}_{2} \mathrm{O}_{3}$ by RPRF process that was $49 \mathrm{HV} 10$, this is influenced by the bonding between the matrix to the reinforcement is good formed. Bonding of composite microstructure is marked by the presence of a line on the boundary bond [14], as shown in Figure 3 of the microstructure. Among the comparable processes, Composite of $\mathrm{Al} / \mathrm{SiC}$ by RPRF has a missing line that dominates along the interface line. Based on grain boundaries, the RPRF method is able to produce UFG of 0.9 compared to other processes. However, grain refinement with increased hardness accompanied by decreased elongation to $0.5 \%$. 
Table 1. Mechanical properties of Composite based aluminum by SPD.

\begin{tabular}{|c|c|c|c|c|}
\hline SPD Process & Hardness (VH10) & Grains Size ( $\boldsymbol{\mu m})$ & $\begin{array}{c}\text { Ultimate Tensile } \\
\text { Strength (MPa) }\end{array}$ & $\begin{array}{c}\text { Elongation } \\
\mathbf{( \% )}\end{array}$ \\
\hline ECAP & 65 & 5.7 & 124 & 3 \\
\hline MAF & 46 & 1.2 & 237 & 8 \\
\hline ARB & 50 & 1.4 & 102 & 7 \\
\hline RPRF & 88 & 0.9 & 147 & 0.5 \\
\hline
\end{tabular}

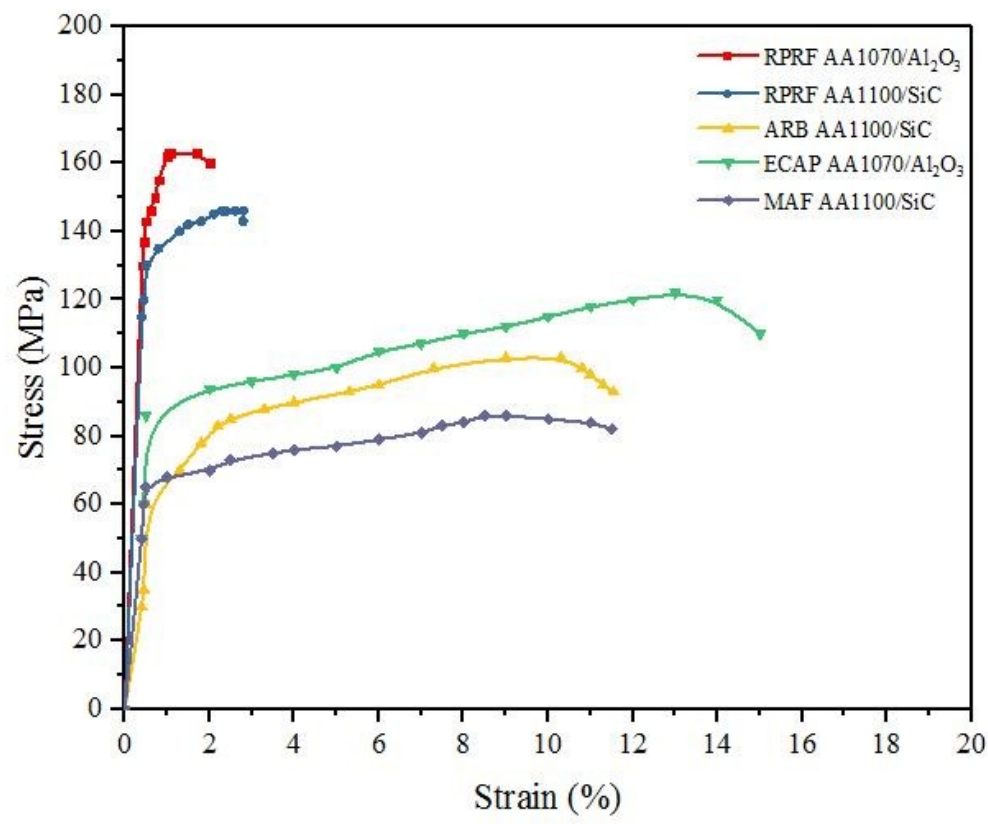

Fig 3. Stress Strains of Aluminum based composite by SPD technology

In other hand MAF method is capable of producing the highest tensile strength of $237 \mathrm{MPa}$, the increase is accompanied by significant elongation reaching $8 \%$, the highest compared to other processes, but the grain gain reaches only $1.2 \mu \mathrm{m}$. The ECAP and ARB processes result in relatively identical mechanical properties, ie 65 VH10 ECAP results and 50 results from ARB, tensile strength for ECAP $124 \mathrm{MPa}$ and on ARB of $102 \mathrm{MPa}$. Improvements in the SPD ECAP and ARB processes require long cycles to improve mechanical properties and fine grain performance. In ECAP, to produce fine grains with high mechanical properties required 4-6 times cycles of pressing [15], whereas ARB requires 8-12 cycles' compression of rolling for significant mechanical properties improvement with fine grain achievement [5].

\subsection{Application Area of Severe Plastic Deformation (SPD) Technology}

The markets of materials produced by the SPD technology being exist in the sectors where highest of properties, such as; specific strength or increased fatigue life, are needed. Hardness and tensile strength is important properties for component application. Formal market analysis specializing in innovation metals production was conducted by company of Metallicum. It has found more than 100 specific markets for production of component in areas on aerospace, transportation, medical equipment, chemical processing, electronics and 
defence [1]. Some of the applications that use SPD materials are aluminum based composites with high yield strength and superplastic properties, higher mechanical properties in cold and cryogenic temperatures and high-strength lightweight alloys with shape-memory effect for space, medical and many other applications [17-18]
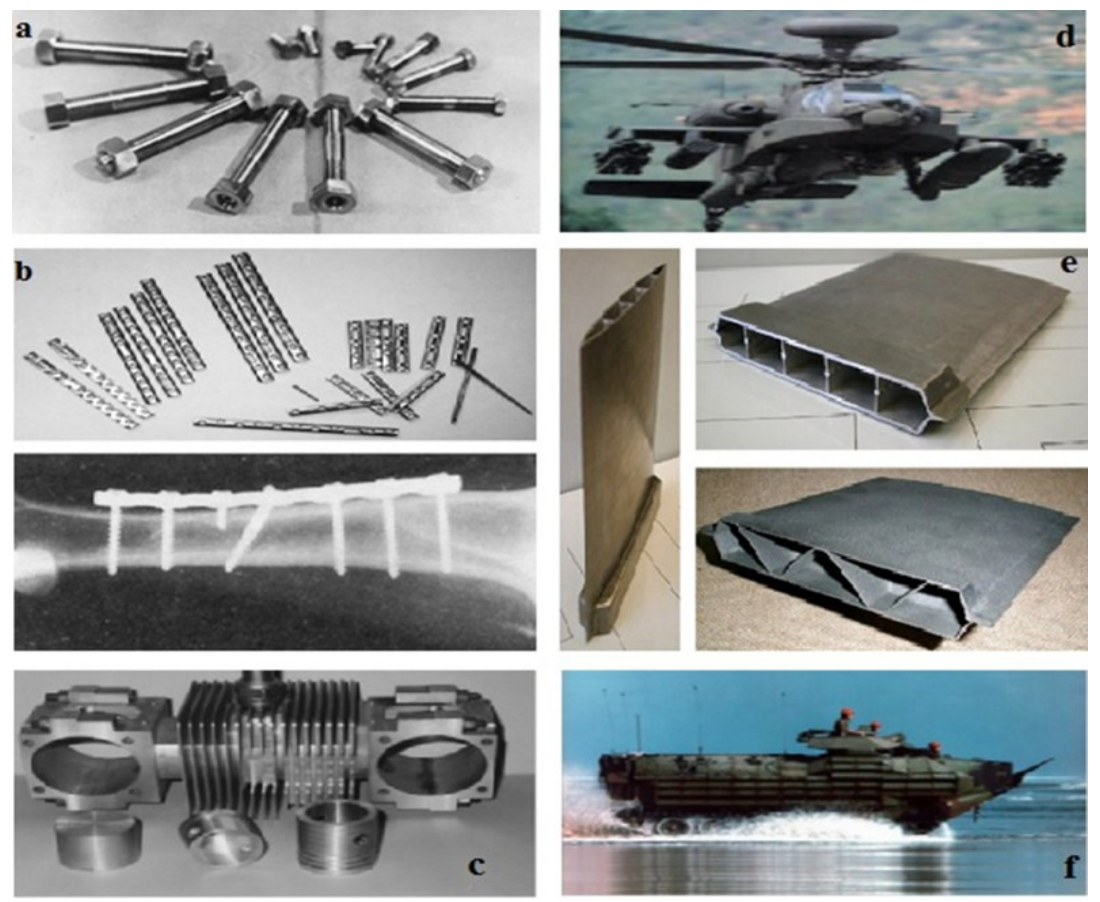

Fig 4. The application of Severe Plastic Deformation: a) Bolt nut connection; b) plate implants made of nanostructure metal; c) engine block machine fabricated from AA1420 by ECAP; d) body of military helicopter from high strength materials; e) Super-plasticity sheet materials for Models of hollow blades from Ti-6Al-4V. f) military device - amphibious assault vehicle, courtesy of BAE Systems by ARB.

\section{Conclusion}

The comparation research of SPD Technology showed the applicability of kind of SPD: ECAP, MAF, ARB and new methods of RPRF for producing composite based aluminium with $\mathrm{SiC}$ and $\mathrm{Al}_{2} \mathrm{O}_{3}$ as reinforcement. The Technology of SPD has a potential for manufacturing aluminum based composites, to produce the ideal tensile strength MAF is the right process for its application, Producing ideal tensile strength MAF is an appropriate process for its application, rather than an ECAP or ARB process, the MAF process is more appropriate for processing Aluminum-based composites in producing high mechanical properties. Development of the latest SPD technology RPRF is present as specific for the processing of aluminum-based composite materials, in the process procedure have 2 stages, namely repeated pressure to immerse the reinforcement particles and rollers to distribute the reinforcement to evenly. 


\section{Acknowledgements:}

The principal author is thankful to Faculty Engineering - University of Sultan Ageng Tirtayasa, for supported research grant "Hibah Penelitian Dosen Madya".

\section{References}

1. Agus Pramono, Investigation of Severe Plastic Deformation Processes for Aluminum Based Composites. Ph.D. Dissertation, Department Mechanical Engineering. Tallinn University of Technology., Tallinn-Estonia, (2016).

2. Senkov, O.N.; Miracle, D.B.; Scott, J.M.; Senkova, S.V., Equal channel angular extrusion compaction of semi-amorphous A185Ni10Y2.5La2.5 alloy powder, Journal of Alloys and Compounds, 1,365, 126-133 (2004).

3. Robertson, J.; Im, J.T.; Karaman, I.; Hartwig, K.T.; Anderson, I.E., Consolidation of amorphous copper based powder by equal channel angular extrusion, Journal of NonCrystalline Solids, 1-2, 144-151, 317 (2003).

4. Megumi Kawasaki, Yi Huang, Cheng Xu, Minoru Furukawa, Zenji Horita, Terence G. Langdon. Quantitative study of cavity development in the tensile testing of an aluminum metal matrix composite processed by equal-channel angular pressing. Materials Science and Engineering A. 402-407, 410 (2005).

5. Argentero, S., Accumulative roll bonding technology of aluminum alloys, Proceedings of Strategic Management Factors of MNC's Subsidiaries-Comparative Analysis of Metal Manufacturing and Other Industries in the Czech Republic, 1-6 (2012).

6. Sajjad Amirkhanlou, Mostafa Ketabchi, Nader Parvin, Shohreh Khorsand, Reza Bahrami.Accumulative press bonding; a novel manufacturing process of nanostructured metal matrix composites. Materials and Design, 367-374, 51, (2013).

7. Sajjad Amirkhanlou, Mostafa Ketabchi, Nader Parvin, Shohreh Khorsand and Fernando Carreño. Manufacturing of nanostructured Al/WCp metalmatrix composites by accumulative press bonding. IOP Conf. Series: Materials Science and Engineering 63 (2014) (6th International Conference on Nanomaterials by Severe Plastic Deformation IOP Publishing).

8. Sajjad Amirkhanlou, Masoomeh Askarian, Mostafa Ketabchi, Navvid Azimi, Nader Parvin, Fernando Carreño. Gradual formation of nano/ultrafine structure under accumulative press bonding (APB) process. Materials Characterization, 57-65, 109 (2015).

9. Sajjad Amirkhanlou, MostafaKetabchi, NaderParvin, Masoomeh Askarian, Fernando Carreño. Achieving ultrafine grained and homogeneous AA1050/ZnO nano composite with well-developed high angle grain boundaries through accumulative press bonding. Materials Science \& Engineering A, 374-380, 627 (2015).

10. Agus Pramono, Lauri Kollo and Renno Veinthal, Aluminum based composite by novel process: repetitive press roll bonding (RPRB), Procedia Chemistry, 473-479, 16 (2015).

11. Agus Pramono, Merging method of aluminum fiber composite materials with alternating pressure and rolling process using Repetitive Press Roll Forming technology. Application number: 001/P/ HKI/2000. University of Sultan Ageng Tirtayasa Banten. Patent, P00201709889 (2017).

12. Agus Pramono, Lauri Kollo, Kaspar Kallip, Renno Veinthal and Jaana-Kateriina Gomon. Heat Treatment of Ultrafine Grained High-Strength Aluminum Alloy. Key Engineering Materials Vol. 604 pp 273-276 (2014).

13. Zrink J, Dobatkn V, Mamuzic I. Processing Of Metals By Severe Plastic Deformation (SPD) - Structure And Mechanical Properties Respond. Metalurgija. 47 (3) 211-216 (2008). 
14. Agus Pramono, Lauri Kollo and Renno Veinthal. Hot and cold regions during accumulative roll bonding of $\mathrm{Al} / \mathrm{Al}_{2} \mathrm{O}_{3}$ nanofibre composites Proceedings of the Estonian Academy of Sciences. 65, 2, 132-137 (2016)

15. Agus Pramono. Lembit Kommel. Lauri Kollo and RennoVeinthal, Hot and Cold of Pressing Effect on ECAP-Parallel Channel Composite Based on Al/ANF Material, Advanced Materials Research. 1123: 343-347 (2015).

16. Agus Pramono, Lauri Kollo, Kaspar Kallip, Renno Veinthal and Jaana-Kateriina Gomon. Heat Treatment of Ultrafine Grained AA6061 Consolidation by Equal Channel Angular Pressing. Applied Mechanics and Materials Vol 771, pp 252-256 (2015).

17. Agus Pramono, Anistasia Milandia, Kurnia Nugraha and Moch Fawaid. Aluminum Alloys by ECAP Consolidation For Industrial Application. VANOS Journal of Mechanical Engineering Education. Vol 2. 2 . 117-125 (2017).

18. Agus Pramono. The new of technology Severe plastic deformation (SPD) For Military Device Applications. Journal DEFENDONESIA. Vol 3, 1: 10-18 (2017). 